\title{
Risky Behaviors among HIV-Positive Female Sex Workers in Northern Karnataka, India
}

\author{
Apoorva Jadhav, ${ }^{1}$ Parinita Bhattacharjee, ${ }^{2}$ T. Raghavendra, ${ }^{2}$ James Blanchard, ${ }^{3}$ \\ Stephen Moses, ${ }^{3}$ Shajy Isac, ${ }^{2}$ and Shiva S. Halli ${ }^{3}$ \\ ${ }^{1}$ Population Studies Center, University of Pennsylvania, 3718 Locust Walk, 239 McNeil Building, Philadelphia, PA 19103, USA \\ ${ }^{2}$ Karnataka Health Promotion Trust, Bangalore 560044, India \\ ${ }^{3}$ Centre for Global Public Health, University of Manitoba, Winnipeg MB, Canada R3E 0T6
}

Correspondence should be addressed to Apoorva Jadhav; apoorvaj@sas.upenn.edu

Received 6 September 2012; Accepted 18 December 2012

Academic Editor: P. K. Nicholas

Copyright (C) 2013 Apoorva Jadhav et al. This is an open access article distributed under the Creative Commons Attribution License, which permits unrestricted use, distribution, and reproduction in any medium, provided the original work is properly cited.

\begin{abstract}
Purpose. Little is known about the risky sexual behaviors of HIV-positive female sex workers (FSWs) in the developing world, which is critical for programmatic purposes. This study aims to shed light on their condom use with regular clients as well as husband/cohabiting partner, a first in India. Methods. Multivariate logistic regression analyses for consistent condom use with regular clients and husband/cohabiting partner are conducted for the sample of 606 HIV-positive FSWs. Results. Older FSWs are 90\% less likely and nonmobile FSWs are 70\% less likely to consistently use condoms. FSWs on ART are 3.84 times more likely to use condoms. Additionally, FSWs who changed their occupation after HIV diagnosis are 70\% less likely to use condoms. FSWs who are currently cohabiting are more likely to consistently use condoms with repeat clients and are 3.22 times more likely to do so if they have felt stigma associated with being HIV-positive. FSWs who have multiple repeat clients, and who do not know the sexual behavior of these clients, are more likely to use condoms consistently. Conclusion. This study would help inform programs to target the following particularly vulnerable HIV-positive FSWs: those who are older, those who changed their occupation post-HIV diagnosis, and those who are nonmobile.
\end{abstract}

\section{Introduction}

While overall HIV prevalence is low, India has the third largest number of people living with HIV/AIDS in the world [1]. Sexual transmission of HIV is the most dominant route of infection in the country and is concentrated among high risk groups, particularly female sex workers (FSWs), their clients, men who have sex with men (MSM), and injection drug users. Sentinel surveillance data from 2008-2009 indicates that $7.2 \%$ of injecting drug users, $7.4 \%$ of MSM, and $5.1 \%$ of FSWs are HIV-positive, in stark contrast to the $0.5 \%$ of attendees in antenatal clinics who tested positive [1]. These indicators suggest that the HIV epidemic in India is in its concentrated phase. FSWs have long been acknowledged as one of the primary drivers of sexually transmitted infections in developing countries [2,3] and HIV in particular [4]. Due to the larger number of sexual partners compared to other populations, FSWs are at a higher risk of becoming infected and infecting their clients and other partners. Direct interventions among vulnerable groups like FSWs can prove to be very effective in India; Nagelkerke et al. [5] predict that effective HIV intervention among FSWs in the country can drive the epidemic to its extinction.

National HIV prevalence among FSWs is estimated at $4.9 \%$, but there is much geographical variation. Sentinel data indicate that at the state level, the highest HIV prevalence among FSWs is in Maharashtra (17.9\%) and Manipur (13.1\%), followed by Andhra Pradesh (9.7\%), and Karnataka (5.3\%) [6]. In addition to health problems, HIVpositive FSWs who know their HIV status are confronted with a multitude of decisions including those related to safe sex practices. Condom negotiation with clients and husband/cohabiting partner as well as consistent condom use regardless of type of client (regular, occasional, new) are 
complicated for FSWs as a whole, but take on a different dimension for FSWs who are HIV-positive. Although there are numerous studies conducted among FSWs regarding their risky sexual behaviors $[2,3,7,8]$, not a single study exits to the authors' knowledge on the nature of sex work practice among HIV-positive FSWs in India. The only other study that assesses these relationships finds that HIV-positive FSWs in China had more clients per month and used condoms consistently with regular partners than HIV-negative FSWs [9]. The sample size for that analysis was based on $47 \mathrm{HIV}-$ positive FSWs in one city in China, thus was not generalizable to a larger population. In Karnataka, mapping exercises in 18 districts of the state indicate that there are 80,000 FSWs. If we assume an overall HIV prevalence of $15 \%$, there will be 12,000 FSWs who are HIV-positive. Given the sheer number of HIV-positive FSWs in India, the findings of this study to understand condom use among FSWs and their regular clients and husband/cohabiting partner are particularly salient from a programmatic perspective.

\section{Materials and Methods}

The data used for this study come from a cross-sectional quantitative survey of HIV-positive FSWs in three corridor districts in the south Indian state of Karnataka-Bagalkot, Belgaum, and Bijapur, conducted by the Karnataka Health Promotion Trust (KHPT). The data were collected for a period of 6 months, beginning from July to end of December 2011, and were analyzed in 2012.

2.1. Sampling. The sampling frame for the study is a list of FSWs who tested positive for HIV in the study districts. The FSWs are referred to HIV testing by KHPT peer educators and are followed up to ensure they have visited the Integrated Counseling and Testing Center (ICTC) and undergone HIV testing. If the tested FSWs disclose their HIV status to the peer educators, they are recorded as part of the program monitoring system and followed up for services including pre-ART registration, CD4 tests, and ART treatment. The sample size for each study domain (district) was determined using the expected baseline value of $50 \%$ and a desired change in the baseline value of 10-15\% with a design effect of 1.5. Based on this, the sample size was fixed at $339 \mathrm{HIV}$ positive FSWs per study domain. Additionally, assuming $10 \%$ nonresponse, the sample size was inflated to account for those instances. The final response rate was about $66 \%$, which is high given the highly stigmatized population of study interest. Although the nonresponse rate of $33 \%$ is not desirable, it is to be noted that there were no significant differences by district especially in terms of their background characteristics except in their marital status, more Devadasis (Devadasis historically refer to a class of women who are ceremoniously married to gods or deities, and typically have socially sanctioned sexual liaisons with patrons. For a detailed discussion of the history and nuances of the tradition, refer to Srinivasan's 1985 piece "Reform and Revival: The Devadasi and her Dance [10]") in Bagalkot district and more married sex workers in Belgaum district. These differences can be accounted for by controlling for the marital status variable. Hence, the analysis for this paper is performed for the pooled data of each domain separately so that there will be enough cases for both cross tabular and multivariate analyses.

2.2. Selection of Respondents within a Domain (District). The sample respondents were selected using stratified random sampling, with rural-urban residence as the first level, and taluka (an administrative subdivision consisting of towns and surrounding villages) as a second level of stratification. The age of respondents was considered as an implicit stratification variable so as to have a representative sample of the district. Once the list of HIV-positive FSWs was organized by stratification, a systematic random selection process was done to ensure that the sample respondents would be selected in proportion to the total number of positive FSWs in each stratum. The final sample size for completed interviews was 255 in Bagalkot district, 239 in Belgaum district, and 112 in Bijapur district for a total of size of $606 \mathrm{HIV}$-positive FSWs interviewed.

2.3. Consent Process. The HIV status of FSWs is known only to the FSWs and peer educators, thus ensuring trust and communication between the two was critical. Prior to the survey, all the peer educators underwent a training program on the process, confidentiality, and expected roles and responsibilities. Additionally, the peer educators were the mediators who explained the objectives and expected outcome of the study with the HIV-positive FSWs. Only if the participating provided written and informed consent for the interview were they included in the final study interview process.

2.4. Ethical Approval and Consent Process. Institutional review board at the St. John's Medical College, Bangalore, India, provided ethical approval for the study. The HIV status of the FSW is known only to the FSW and peer educators, thus ensuring trust and communication between the two was critical. Prior to the survey, all the peer educators underwent a training program on the process, confidentiality, and expected roles and responsibilities. Additionally, the peer educators were the mediators who explained the objectives and expected outcome of the study with the HIVpositive FSW. Only if the participating provided written and informed consent for the interview were they included in the final study interview process.

2.5. Statistical Analysis. Once data editing, entry, and cleaning were completed by trained staff at KHPT, the data were analyzed using STATA, version 11.0. The frequencies and bivariate analysis were generated using this software. The multivariate analyses of consistent condom use with regular clients and husband/cohabiting partner were calculated along with $95 \%$ confidence intervals using logistic regression models. 


\section{Results}

3.1. Sociodemographic Analysis. Of the 606 HIV-positive FSWs in the analysis, $93.6 \%$ were above age 25 , with $46.5 \%$ between the ages of $25-34$, and $47.0 \%$ above age 35 . Threefourths $(73.1 \%)$ of the respondents were nonmobile (in these analyses, "mobile" FSWs refer to migrant or nonlocal women, and "nonmobile" refers to women who are local to the study area) residents and were predominantly Hindu (92.9\%). As Table 1 shows, while most respondents were uneducated $(82.5 \%)$, about $4.8 \%$ received more than 8 years of schooling. Sex work was not the sole occupation of a majority of respondents, with $66.7 \%$ engaged in another occupation. Additionally, $20 \%$ of respondents changed their occupation after a positive HIV diagnosis. There was no interdistrict variation between the respondents except for marital status, which is shown in Table 1. About 15\% of respondents in Belgaum are married, compared to a much lower $2.4 \%$ in Bagalkot and $4.5 \%$ in Bijapur; $82 \%$ of respondents in Bagalkot are Devadasi, while $36.4 \%$ of respondents in Belgaum are widowed. Due to the lack of variation in most characteristics and small number of cases for each district, for subsequent multivariate analysis the data from all three districts are pooled with a control for district.

3.2. Sex Work and Condom Use. Of all the respondents, $19.9 \%$ move from their place of residence for sex work (Table 2). Of those, $13.2 \%$ travel every day, $53.7 \%$ travel once a week, while $21.5 \%$ travel multiple times in a week (Table 2). Most of the respondents were sex workers for duration of greater than 5 years; of those, $22.9 \%$ reported working between 5-9 years, while a much larger $64.7 \%$ reported working for greater than 10 years. Notably, the practice of sex work of FSWs was largely unknown to their husband/cohabiting partner, with $73.9 \%$ unaware about their partner's sex work. Interestingly, $47.7 \%$ of respondents believed that their husband/cohabiting partner has sexual relationships with other women, while $11.9 \%$ did not know. Multiple sexual partners were reported by the respondents themselves, however, with $56.6 \%$ of FSWs reporting having had sex with any nonpaying partner other than their husband/cohabiting partner. These nonpaying partners include police, pimps, and "special friends". In terms of the nature of sex work, there was not much variation in number of clients per day, with a third reporting each: one, two, and three or more clients per day. In contrast, $18.6 \%$ of all respondents had one repeat client per day, while $40.1 \%$ had more than three repeat clients per day. The familiarity with repeat clients did not translate into knowledge of the number of sexual partners: $42.3 \%$ of the respondents did not know if the repeat clients had sex with other women. Finally, consistent condom use varied by type of partner: $32.9 \%$ with husband/cohabiting partner, $85 \%$ with nonpaying partner, and $73.3 \%$ with repeat clients. For multivariate analysis, we did not include occasional nonpaying partner as a dependent variable because the condom use among these clients was more than $75 \%$, our cut-off for consideration for separate analysis.
3.3. Multivariate Analysis. The multivariate logistic regression results are conducted separately for two dependent variables: consistent condom use with husband/cohabiting partner (no/yes), and consistent condom use with repeat client (no/yes). Each model included controls for sociodemographic variables included in Table 1 and controls for district.

(i) Columns 2 and 3 of Table 3 refer to the logistic regression for consistent condom use with husband/ cohabiting partner. The results indicate that older FSWs are $90 \%$ less likely to consistently use condoms compared to younger FSWs and nonmobile FSWs are $70 \%$ less likely to consistently use condoms compared to mobile FSWs. On the other hand, FSWs on ART are 3.84 times more likely to use condoms. Additionally, the number of clients per day is significant, with the odds of consistent condom use with husband/cohabiting partner increasing as the number of clients per day increases.

(ii) Columns 4 and 5 of Table 3 refer to the logistic regression for consistent condom use with repeat clients. These results also find that nonmobile FSWs are less likely to use condoms than their mobile counterparts, and that FSWs who changed their occupation after HIV diagnosis are $70 \%$ less likely to use condoms that those who did not change their occupation. On the other hand, FSWs who are currently cohabiting are more likely to consistently use condoms with repeat clients, and are 3.22 times more likely to do so if they have felt any stigma associated with being HIVpositive. Notably, FSWs who have multiple repeat clients, and who do not know whether their repeat clients have sex with other women are significantly more likely to use condoms consistently.

\section{Discussion}

Other research in South India has found that inconsistent condom use with nonpaying partners or regular clients was based on the level of HIV risk perception by the FSWs [8]. Our study is unique in that the entire sample consists of HIVpositive FSWs, in order to better understand their risk-taking behaviors in light of their HIV status. Findings from this study indicate that older FSWs are less likely to consistently use condoms with their husband/cohabiting partner. This corresponds with the notion that older FSWs tend to be married and more dependent on their husband/cohabiting partner, so there is less negotiation in terms of condom use. This still indicates high-risk behavior since the husband/cohabiting partner does not always know the HIV status of his wife.

While $12.2 \%$ of all respondents report consistent condom use with their husband/cohabiting partner when their HIV status is known to the partner, about $23.1 \%$ of FSWs do not consistently use condoms even though their HIV status is not known to their partner. Contrary to previous arguments [11], FSWs are less likely to consistently use condoms with their husband/cohabiting partner and repeat clients than mobile FSWs. Mobile FSWs are considered to be at higher 
TABLE 1: Sociodemographic distribution of HIV-positive FSWs in Northern Karnataka, 2011.

\begin{tabular}{|c|c|c|c|c|}
\hline Category & Bagalkot (\%) & Belgaum (\%) & Bijapur (\%) & Total (\%) \\
\hline \multicolumn{5}{|l|}{ Age } \\
\hline$<25$ years & 8.6 & 5.4 & 3.6 & 6.4 \\
\hline $25-34$ years & 49.8 & 42.3 & 48.2 & 46.5 \\
\hline $35+$ years & 41.6 & 52.3 & 48.2 & 47.0 \\
\hline \multicolumn{5}{|l|}{ Place of residence } \\
\hline Mobile & 23.5 & 33.9 & 19.6 & 26.9 \\
\hline Nonmobile & 76.5 & 66.1 & 80.4 & 73.1 \\
\hline \multicolumn{5}{|l|}{ Religion } \\
\hline Hindu & 95.7 & 91.2 & 90.2 & 92.9 \\
\hline Others & 4.3 & 8.8 & 9.8 & 7.1 \\
\hline \multicolumn{5}{|l|}{ Education } \\
\hline None & 82.3 & 81.6 & 84.8 & 82.5 \\
\hline $1-7$ years & 11.4 & 15.1 & 10.7 & 12.7 \\
\hline $8+$ years & 6.3 & 3.4 & 4.5 & 4.8 \\
\hline \multicolumn{5}{|l|}{ Marital status } \\
\hline Married & 2.4 & 15.1 & 4.5 & 7.8 \\
\hline Widowed & 6.7 & 36.4 & 25.9 & 22.0 \\
\hline Devadasi & 82.0 & 24.3 & 44.6 & 52.3 \\
\hline Others & 9.0 & 24.3 & 25.0 & 18.0 \\
\hline \multicolumn{5}{|c|}{ Engaged in occupation besides sex work } \\
\hline Yes & 54.7 & 83.9 & 71.0 & 69.2 \\
\hline No & 45.3 & 16.1 & 29.0 & 30.8 \\
\hline \multicolumn{5}{|c|}{ Changed occupation after diagnosis } \\
\hline Yes & 17.8 & 15.6 & 36.6 & 20.4 \\
\hline No & 82.2 & 84.5 & 63.4 & 79.6 \\
\hline \multicolumn{5}{|l|}{ Currently on ART } \\
\hline Yes & 48.6 & 37.2 & 35.7 & 41.8 \\
\hline No & 51.4 & 62.8 & 64.3 & 58.3 \\
\hline \multicolumn{5}{|c|}{ Duration of program exposure } \\
\hline$<2$ years & 8.7 & 22.7 & 2.7 & 13.1 \\
\hline $3-4$ years & 21.0 & 47.9 & 40.2 & 35.2 \\
\hline $5+$ years & 70.4 & 29.4 & 57.1 & 51.7 \\
\hline Number of respondents & 253 & 238 & 112 & 603 \\
\hline
\end{tabular}

risk of inconsistent condom use with their clients; however, as our findings show, it is the nonmobile FSWs who are less likely to consistently use condoms. Mobile sex workers tend to practice sex work in brothels or formalized set ups and are more likely to get support for condom negotiation with clients besides being more exposed to the program. The program activities include condom demonstration, condom negotiation with paying/nonpaying partners, and free supply of condoms in addition to empowerment exercises. It is notable that FSWs who changed their occupation after their HIV diagnosis are significantly less likely to use condoms consistently with their repeat clients. A possible explanation can be that these women are driven to sex work due to a drop in their income level, and are thus more vulnerable to the client's demands due to a potential source of income for the day.

The indicators that directly test the relationship between sex work and consistent condom use shed light on the nature of sex work in light of a positive HIV diagnosis for the FSWs. Those FSWs who are currently undergoing ART are more likely to consistently use condoms with their husband/cohabiting partner. FSWs undergoing any treatment regimen are generally more aware of the risks associated with unsafe sex, and the modes of transmission of HIV, thus are more likely to use condoms. It is interesting that this significant relationship only emerges for condom use with husband/cohabiting partner, and not for repeat clients. A sense of familiarity or belonging with a partner may then indicate lower risk taking behaviors. This is confirmed with our findings that as the number of clients per day increase, FSWs are more likely to use condoms with their husband/cohabiting partner. Another subset of FSWs who could require more focused attention are those FSWs who changed their occupation after HIV diagnosis, since they are less likely to consistently use condoms with repeat clients. This occupation change, lack of income, abandonment by 
TABLE 2: Nature of sex work and condom use among HIV-positive FSWs in Northern Karnataka, 2011.

\begin{tabular}{|c|c|c|}
\hline Category & $N$ & $(\%)$ \\
\hline \multicolumn{3}{|l|}{ Mobility for sex work } \\
\hline No & 485 & 80.0 \\
\hline Yes & 121 & 20.0 \\
\hline \multicolumn{3}{|c|}{ Frequency of mobility for sex work } \\
\hline Everyday & 16 & 13.2 \\
\hline Once a week & 65 & 53.7 \\
\hline More than once a week & 26 & 21.5 \\
\hline Fortnightly & 9 & 7.4 \\
\hline Once a month & 5 & 4.1 \\
\hline \multicolumn{3}{|c|}{ Usually under the influence of alcohol during sex work } \\
\hline No & 538 & 88.3 \\
\hline Yes & 68 & 11.7 \\
\hline \multicolumn{3}{|l|}{ Duration in sex work } \\
\hline$<5$ years & 75 & 12.4 \\
\hline $5-9$ years & 138 & 22.9 \\
\hline $10+$ years & 391 & 64.7 \\
\hline \multicolumn{3}{|c|}{ Husband/cohabiting partner knows about sex work } \\
\hline Yes & 46 & 26.1 \\
\hline No & 130 & 73.9 \\
\hline \multicolumn{3}{|c|}{ Husband/cohabiting partner has sexual relationships with other women } \\
\hline Yes & 84 & 47.7 \\
\hline No & 71 & 40.3 \\
\hline Do not know & 21 & 11.9 \\
\hline \multicolumn{3}{|c|}{ Ever had sex with any nonpaying partner other than husband/cohabiting partner } \\
\hline Yes & 343 & 56.6 \\
\hline No & 263 & 43.4 \\
\hline \multicolumn{3}{|l|}{ Number of clients per day } \\
\hline 1 & 193 & 32.9 \\
\hline 2 & 199 & 34.0 \\
\hline $3+$ & 194 & 33.1 \\
\hline \multicolumn{3}{|l|}{ Number of repeat clients } \\
\hline 1 & 63 & 18.6 \\
\hline 2 & 140 & 41.3 \\
\hline $3+$ & 136 & 40.1 \\
\hline \multicolumn{3}{|c|}{ Does repeat client have sex with other women } \\
\hline No & 47 & 13.4 \\
\hline Yes & 156 & 44.3 \\
\hline Do not know & 149 & 42.3 \\
\hline \multicolumn{3}{|c|}{ Consistent condom use with husband/cohabiting partner } \\
\hline No & 120 & 67.0 \\
\hline Yes & 59 & 33.0 \\
\hline \multicolumn{3}{|c|}{ Consistent condom use with repeat client } \\
\hline No & 94 & 26.7 \\
\hline Yes & 258 & 73.3 \\
\hline \multicolumn{3}{|c|}{ Consistent condom use with nonpaying partner } \\
\hline No & 86 & 15.0 \\
\hline Yes & 488 & 85.0 \\
\hline
\end{tabular}


TABLE 3: Odds of consistent condom use with husband/co-habiting partner and repeat clients among HIV-positive FSWs in Northern Karnataka, 2011.

\begin{tabular}{|c|c|c|c|c|}
\hline & \multicolumn{2}{|c|}{ Husband/Cohabiting Partner } & \multicolumn{2}{|c|}{ Repeat Client } \\
\hline & Odds Ratio & $95 \% \mathrm{CI}$ & Odds Ratio & $95 \% \mathrm{CI}$ \\
\hline \multicolumn{5}{|l|}{ Age } \\
\hline \multicolumn{5}{|l|}{$<25$ years } \\
\hline 25-34 years & 0.15 & $(0.02,1.19)$ & 0.65 & $(0.12,3.54)$ \\
\hline $35+$ years & $0.10^{*}$ & $(0.01,1.00)$ & 0.77 & $(0.12,4.81)$ \\
\hline \multicolumn{5}{|l|}{ Place of residence } \\
\hline \multicolumn{5}{|l|}{ Mobile } \\
\hline Nonmobile & $0.31^{*}$ & $(0.10,0.96)$ & $0.29^{*}$ & $(0.10,0.93)$ \\
\hline \multicolumn{5}{|l|}{ Marital status } \\
\hline Married & - & - & & \\
\hline Widowed & - & - & 2.43 & $(0.38,15.48)$ \\
\hline Devadasi & - & - & 1.40 & $(0.22,8.86)$ \\
\hline Others & - & - & 1.75 & $(0.26,11.68)$ \\
\hline \multicolumn{5}{|c|}{ Currently cohabiting } \\
\hline Yes & - & - & & \\
\hline No & - & - & $2.49^{*}$ & $(1.06,5.89)$ \\
\hline \multicolumn{5}{|l|}{ Currently on ART } \\
\hline \multicolumn{5}{|l|}{ No } \\
\hline Yes & $3.84^{* *}$ & $(1.39,10.60)$ & 1.36 & $(0.64,2.86)$ \\
\hline \multicolumn{5}{|c|}{ Feel any stigma associated with being HIV+ } \\
\hline \multicolumn{5}{|l|}{ No } \\
\hline Yes & 2.70 & $(0.94,7.76)$ & $3.22^{* *}$ & $(1.34,7.77)$ \\
\hline \multicolumn{5}{|c|}{ Change in occupation after HIV diagnosis } \\
\hline No & (ref) & & (ref) & \\
\hline Yes & 0.35 & $(0.11,1.13)$ & $0.32^{* *}$ & $(0.14,0.72)$ \\
\hline \multicolumn{5}{|c|}{ Number of clients per day } \\
\hline 1 & (ref) & & (ref) & \\
\hline 2 & $5.44^{*}$ & $(1.01,29.26)$ & 0.44 & $(0.17,1.16)$ \\
\hline $3+$ & $11.10^{* * *}$ & $(2.25,54.68)$ & 0.65 & $(0.23,1.88)$ \\
\hline \multicolumn{5}{|c|}{ Number of repeat clients } \\
\hline 1 & - & & (ref) & \\
\hline 2 & & & 1.31 & $(0.46,3.75)$ \\
\hline $3+$ & & & $3.23^{*}$ & $(1.09,9.55)$ \\
\hline \multicolumn{5}{|c|}{ Repeat client has sex with other women } \\
\hline No & & & (ref) & \\
\hline Yes & & & 1.43 & $(0.49,4.17)$ \\
\hline Do not know & & & $3.25^{*}$ & $(1.00,10.53)$ \\
\hline
\end{tabular}

All models include controls for sociodemographic characteristics and controls for district.

${ }^{*} P<0.05,{ }^{* *} P<0.01,{ }^{* * *} P<0.001$.

spouse or families could indicate that these women may not be as aware of the risks involved with unsafe sex, or more importantly, may not be able to effectively negotiate condom use for fear of being turned away. A study on FSWs in Bangladesh finds that low rate of consistent condom use is a result of clients' dislike of condoms, lack of knowledge, low risk perception, and poor situational availability of condoms. Additionally, the authors find that initiation of condom negotiation by FSWs could trigger violence [7].

Notably, risky sex behavior is reduced with increasing numbers of repeat clients, and FSWs concern about other sexual relationships of their repeat clients. Known risk factors that contribute to the concentrated HIV epidemic in China, Thailand, and Cambodia are low rates of consistent condom use during sex work and concurrent sex with FSWs and other casual or steady partners [12]. The scenario in India is similar, thus targeted interventions for FSWs, particularly HIV-positive FSWs, in curtailing the spread of the epidemic are critical.

Our study has several limitations. First, we do not have a comparison group of HIV-negative FSWs in order to assess the difference in risk taking behavior by HIV status. From 
what we know about HIV-negative FSWs, consistent condom use depends on the level of risk perception based on type of client. Those FSWs have to take appropriate actions to protect themselves in order to remain uninfected. In our study, the onus of responsibility is on the FSWs for another reason-in order to prevent infecting their husband/cohabiting partner or regular client. A second limitation is that questions were not asked on negotiation patterns of condom use. Thus, it is not possible to estimate risk perception on behalf of the clients, in light of knowing and not knowing the HIV status of the FSWs. Finally, we do not know about the alcohol use of clients or partners during sex, which can be correlated with limited condom negotiation.

\section{Conclusion}

These findings are programmatically significant for interventions targeted at HIV-positive FSWs in Karnataka. Older FSWs, those who changed their occupation post-HIV diagnosis, and nonmobile FSWs are particularly vulnerable subpopulations that need pointed interventions. It is interesting to note that sizable proportion of sex workers do not inform their husband/cohabiting partner about their sex work or their HIV status. That means there are some high risk groups of sex workers additional to the ones we know. This information is extremely useful for the programmers working with HIV-positive FSWs in Karnataka. Similarly in case women fear going to program activities because they are HIV-positive and/or married, the program staff would greatly benefit from understanding the main factors that affect this decision and address these issues more effectively during counseling and other components of the intervention. For example, if women are unable to use condoms with their husband/cohabiting partner, the program staff could expand their work and include those partners in their counseling activities. Interventions should also include the family members in particular and communities in general in order to create a more enabling environment for safe sex practice for HIV-positive FSWs.

\section{Conflict of Interests}

Three of the listed authors are affiliated with the KHPT but declare no conflict of interests due to their affiliation or financial assistance that they might have received. Moreover, instrument development and data collection were undertaken by S. S. Halli, while A. Jadhav conducted the data analysis and wrote the paper. All authors in the study declare that there is no conflict of interests and that the contents are solely the responsibility of the authors and do not necessarily represent the official views of the KHPT.

\section{Acknowledgments}

The authors would like to thank all the women who participated in this study. They thank the KHPT study team for all their hard work dedication, and Mr. Satyanarayan for his assistance with field work supervision, and Dr. Ravi Prakash for data cleaning. A. Jadhav would like to acknowledge funding support from The Center for the Advanced Study of India (CASI) at the University of Pennsylvania.

\section{References}

[1] NACO, National AIDS Control Organization Annual Report 2010-11, Ministry of Health and Family Welfare, Government of India, New Delhi, India, 2011.

[2] P. Estebanez, K. Fitch, and R. Najera, "HIV and female sex workers," Bulletin of the World Health Organization, vol. 71, no. 3-4, pp. 397-412, 1993.

[3] L. J. D’Costa, F. A. Plummer, I. Bowmer, L. Fransen, P. Piot, and A. Ronald, "Prostitutes are a major reservoir of sexually transmitted diseases in Nairobi, Kenya," Sexually Transmitted Diseases, vol. 12, no. 2, pp. 64-67, 1985.

[4] F. A. Plummer, N. J. D. Nagelkerke, S. Moses, J. O. NdinyaAchola, J. Bwayo, and E. Ngugi, "The importance of core groups in the epidemiology and control of HIV-1 infection," AIDS, vol. 5, supplement 1, pp. S169-S176, 1991.

[5] N. J. D. Nagelkerke, P. Jha, S. J. de Vlas et al., "Modelling HIV/AIDS epidemics in Botswana and India: impact of interventions to prevent transmission," Bulletin of the World Health Organization, vol. 80, no. 2, pp. 89-96, 2002.

[6] NACO, HIV Sentinel Surveillance and HIV Estimation in India 2007: A Technical Brief, Ministry of Health and Family Welfare, New Delhi, India, 2008.

[7] M. M. Islam and K. M. Conigrave, "HIV and sexual risk behaviors among recognized high-risk groups in Bangladesh: need for a comprehensive prevention program," International Journal of Infectious Diseases, vol. 12, no. 4, pp. 363-370, 2008.

[8] A. Jain, N. Saggurti, B. Mahapatra et al., "Relationship between reported prior condom use and current self-perceived risk of acquiring HIV among mobile female sex workers in Southern India," BMC Public Health, vol. 11, Supplement 6, article S5, 2011.

[9] H. Wang, R. Y. Chen, G. B. Sharp et al., "Mobility, risk behavior and HIV/STI rates among female sex workers in Kaiyuan City, Yunnan Province, China," BMC Infectious Diseases, vol. 10, article 198, 2010.

[10] A. Srinivasan, "Reform and revival: the devadasi and her dance," Economic and Political Weekly, vol. 20, no. 44, pp. 1869-1876, 1985.

[11] Population Council, Assessing the Patterns and Drivers of Migration/Mobility of Sex Workers on the Move in Karnataka and Examining the Link with HIV Risk, Population Council, New Delhi, India, 2010.

[12] H. Yang, X. Li, B. Stanton et al., "Heterosexual transmission of HIV in China: a systematic review of behavioral studies in the past two decades," Sexually Transmitted Diseases, vol. 32, no. 5, pp. 270-280, 2005. 


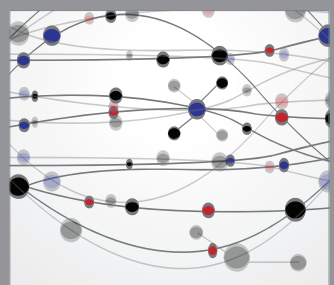

The Scientific World Journal
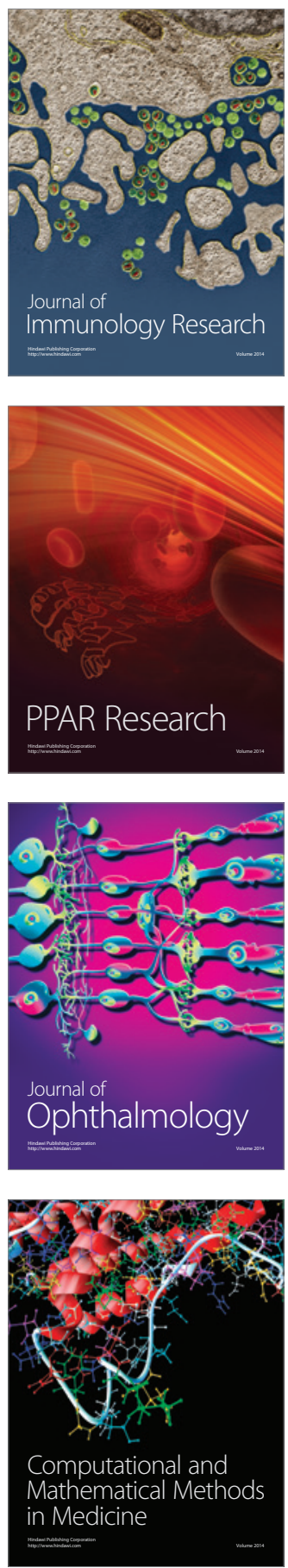

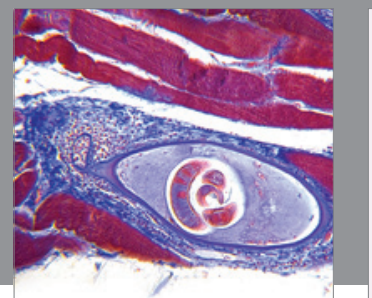

Gastroenterology

Research and Practice
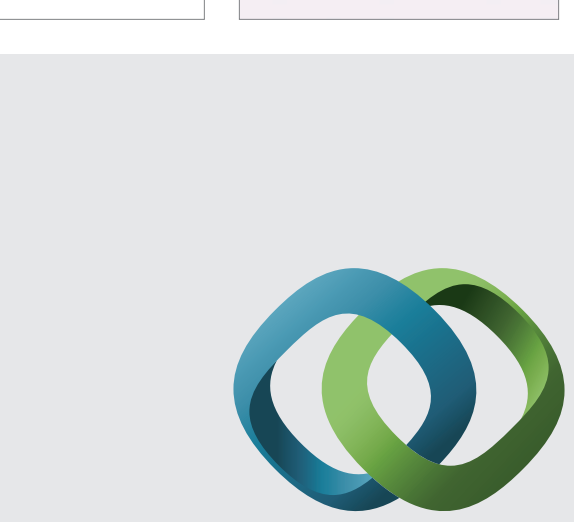

\section{Hindawi}

Submit your manuscripts at

http://www.hindawi.com
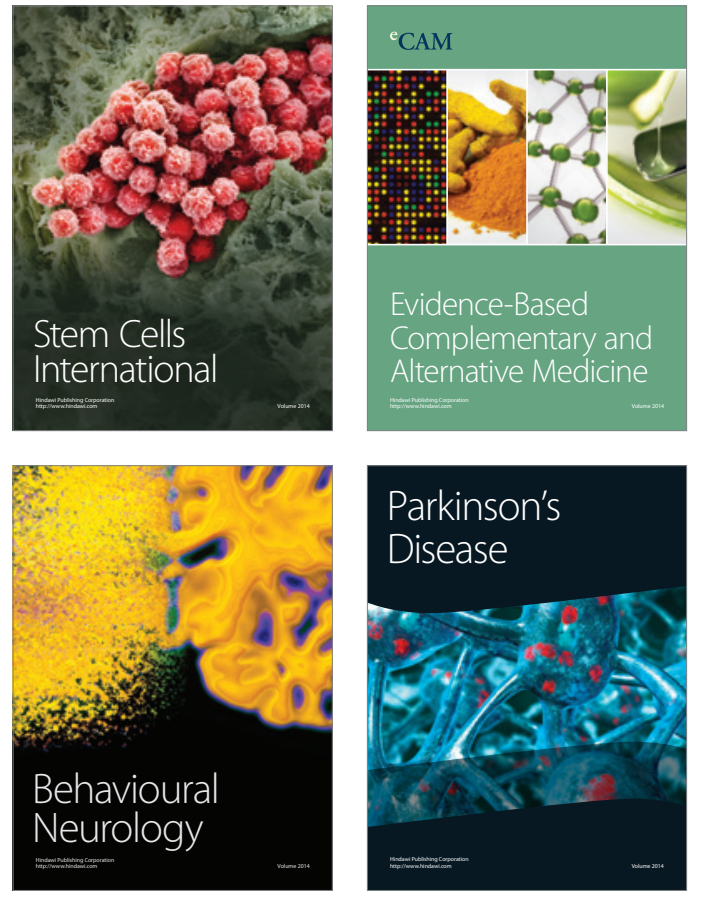
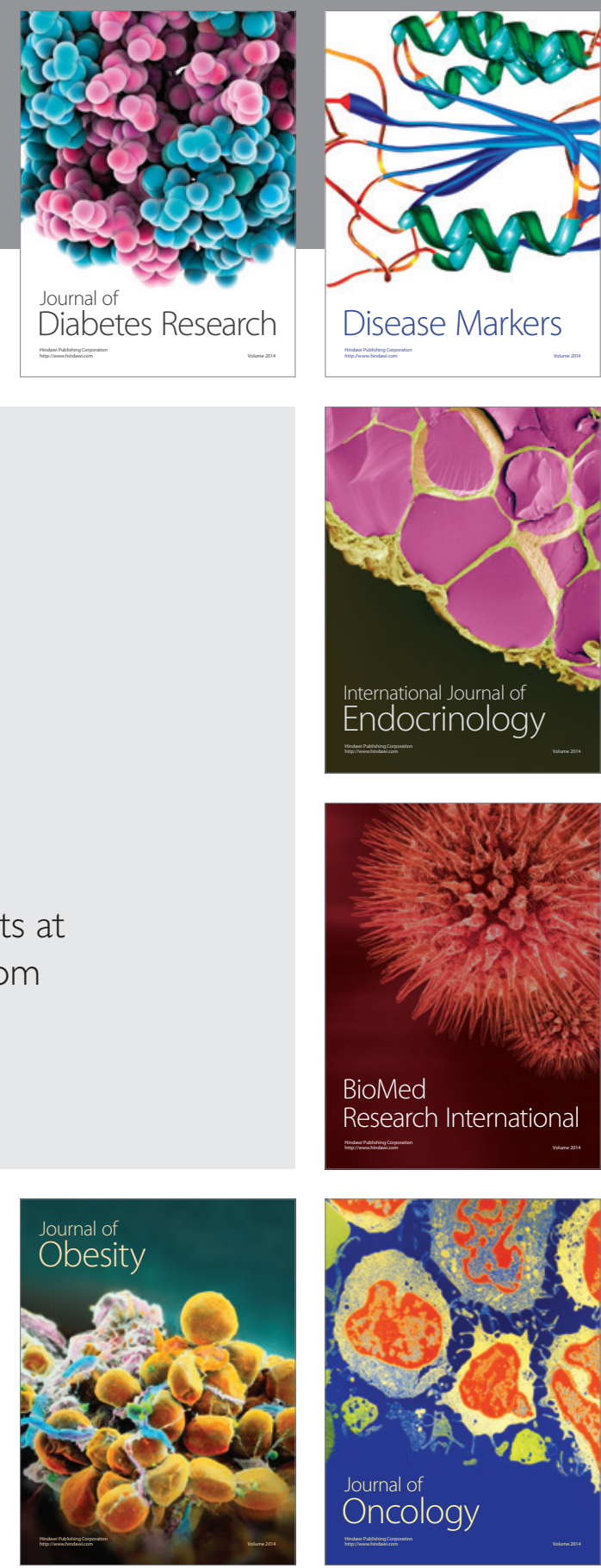

Disease Markers
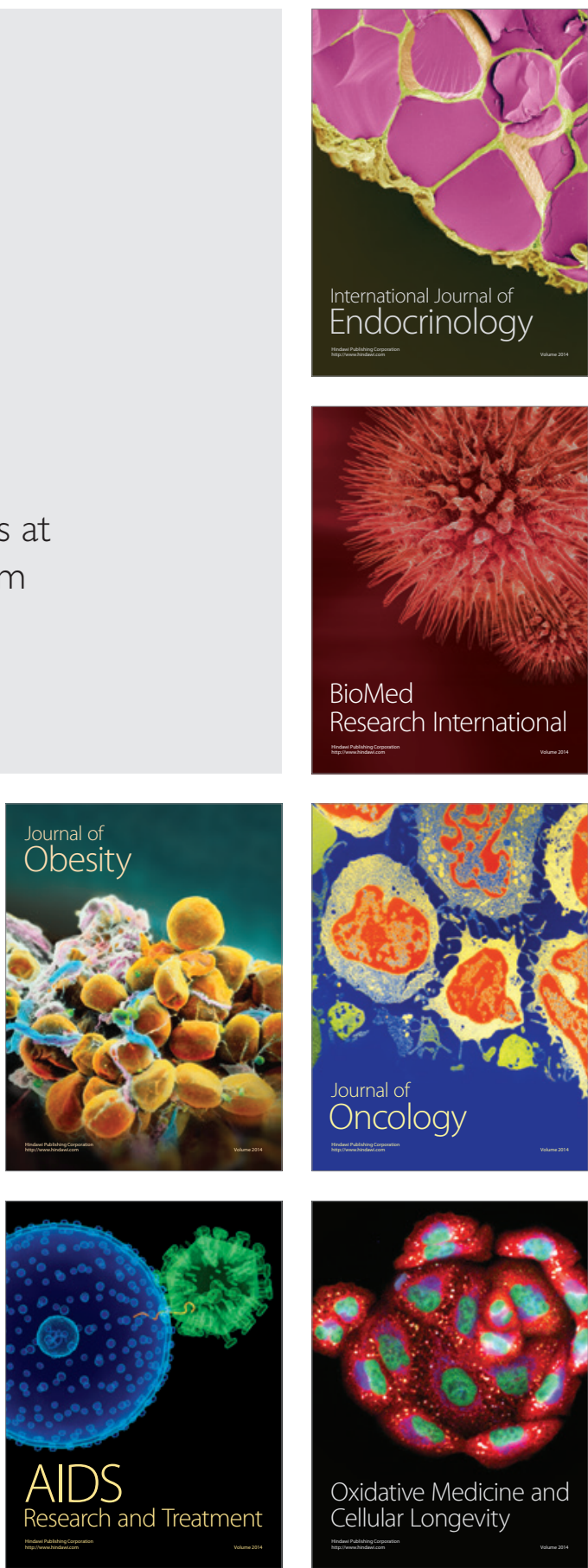